\title{
Prevalence and Predictors of Patient Nonadherence to Pharmacological Acute Pain Therapy at Home After Day Surgery
}

Citation for published version (APA):

Stessel, B., Theunissen, M., Marcus, M. A., Joosten, E. A., van Kuijk, S. M. J., Fiddelers, A. A. A., Peters, M. L., Hoofwijk, D. M. N., Buhre, W. F. F. A., \& Gramke, H-F. (2018). Prevalence and Predictors of Patient Nonadherence to Pharmacological Acute Pain Therapy at Home After Day Surgery: A Prospective Cohort Study. Pain Practice, 18(2), 194-204. https://doi.org/10.1111/papr.12589

Document status and date:

Published: 01/02/2018

DOI:

10.1111/papr.12589

Document Version:

Publisher's PDF, also known as Version of record

Document license:

Taverne

Please check the document version of this publication:

- A submitted manuscript is the version of the article upon submission and before peer-review. There can be important differences between the submitted version and the official published version of record.

People interested in the research are advised to contact the author for the final version of the publication, or visit the DOI to the publisher's website.

- The final author version and the galley proof are versions of the publication after peer review.

- The final published version features the final layout of the paper including the volume, issue and page numbers.

Link to publication

\footnotetext{
General rights rights.

- You may freely distribute the URL identifying the publication in the public portal. please follow below link for the End User Agreement:

www.umlib.nl/taverne-license

Take down policy

If you believe that this document breaches copyright please contact us at:

repository@maastrichtuniversity.nl

providing details and we will investigate your claim.
}

Copyright and moral rights for the publications made accessible in the public portal are retained by the authors and/or other copyright owners and it is a condition of accessing publications that users recognise and abide by the legal requirements associated with these

- Users may download and print one copy of any publication from the public portal for the purpose of private study or research.

- You may not further distribute the material or use it for any profit-making activity or commercial gain

If the publication is distributed under the terms of Article $25 \mathrm{fa}$ of the Dutch Copyright Act, indicated by the "Taverne" license above, 


\section{ORIGINAL ARTICLE}

\section{Prevalence and Predictors of Patient Nonadherence to Pharmacological Acute Pain Therapy at Home After Day Surgery: A Prospective Cohort Study}

Björn Stessel (1), $\mathrm{PhD}^{*,+}$; Maurice Theunissen, $\mathrm{MSc}^{\dagger}$; Marco A. Marcus, $\mathrm{PhD}^{\dagger, \ddagger}$; Elbert A. Joosten, $\mathrm{PhD}^{\dagger}$; Sander M. J. van Kuijk, $\mathrm{PhD}^{\mathbb{\$}}$; Audrey A. A. Fiddelers, $\mathrm{PhD}^{\dagger, \mathbb{I l}}$; Madelon L. Peters, PhD**; Daisy M. N. Hoofwijk, $\mathrm{MD}^{\dagger}$; Wolfgang F. F. A. Buhre, $\mathrm{PhD}^{\dagger}$; Hans-Fritz Gramke, $\mathrm{PhD}^{\dagger}$

*Department of Anesthesiology and Pain Medicine, Jessa Hospital, Hasselt, Belgium; ${ }^{\dagger}$ Department of Anesthesiology and Pain Medicine, Maastricht University Medical Center, Maastricht, The Netherlands; ${ }^{\ddagger}$ Department of Anesthesia/ICU and Perioperative Medicine, Hamad Medical Corporation, Doha, Qatar; ${ }^{\circledR}$ Department of Clinical Epidemiology and Medical Technology Assessment, Maastricht University Medical Center, Maastricht, The Netherlands;

"Network Acute Care Limburg, Maastricht, The Netherlands; **Department of Clinical Psychological Science, Maastricht University Medical Center, Maastricht, The Netherlands

\section{Abstract}

Background: Good adherence to prescribed analgesics can be crucial to suppress or even prevent acute postoperative pain after day surgery. The aim of this study was to analyze prevalence and predictors of analgesic nonadherence after day surgery.

Methods: Elective patients scheduled for day surgery were prospectively enrolled from November 2008 to April 2010. Outcome parameters were measured by using questionnaire packages at 2 time points: 1 week preoperatively and 4 days postoperatively. The primary outcome parameter was

Address correspondence and reprint requests to: Björn Stessel, MD, Department of Anesthesiology and Pain Treatment, Jessa Hospital, Hasselt, Virga-Jesse Campus, Stadsomvaart 11, 3500 Hasselt, Belgium. E-mail: bjornstessel@hotmail.com.

Submitted: October 4, 2016; Revised March 19, 2017; Revision accepted: March 30, 2017

DOI. 10.1111/papr.12589 analgesic nonadherence. Adherence was defined according to the patient's response to the questionnaire item "analgesia use as prescribed": full adherence, "yes"; partial adherence, "yes, sometimes"; nonadherence, "no." Bivariate and multivariate logistic regression analyses were performed to identify predictors of analgesic nonadherence.

Results: A total of 1,248 patients were included. The prevalence rates of analgesic nonadherence and partial adherence were $21.6 \%$ and $20.0 \%$, respectively, in the total study population but dropped to $9.4 \%$ and $19.8 \%$, respectively, in patients with moderate to severe pain. Low postoperative pain intensity and short duration of surgery were the most important predictors of analgesic nonadherence. The most important preoperative predictors for analgesic nonadherence were low preoperative pain intensity, low preoperative expectations of pain, and low fear of short-term effects of surgery.

Conclusion: Analgesic nonadherence and partial adherence are common after day surgery but decrease as average pain intensity increases. Patients at risk for analgesic nonadherence can be identified during the preoperative period based on preoperative pain intensity, preoperative expectations of pain, and fear of surgery. 
Key Words: analgesia, pain, postoperative, pain assessment

\section{INTRODUCTION}

Despite increased awareness and improvements in postoperative pain management over the past decades, the prevalence of outpatients suffering moderate to severe acute postoperative pain at home still remains high and varies from $9 \%$ to $40 \%{ }^{1-5}$

However, sufficient control of postoperative pain is essential as acute postoperative pain is an important risk factor for the development of chronic postsurgical pain $^{6-8}$ and can cause unanticipated hospital admission of outpatients. ${ }^{9-11}$

Obviously, good adherence to prescribed postoperative pain medication can be crucial to suppress or even prevent moderate to severe acute postoperative pain after day surgery. Medication adherence or compliance is defined as "the extent of correspondence between the patient's actual dosing history and the prescribed regimen." ${ }^{12}$ Furthermore, the National Institute for Health and Clinical Excellence (NICE) guidelines posit that "adherence presumes an agreement between prescriber and patient about the prescriber's recommendations." 13,14

There are many causes of nonadherence, but they fall into 2 overlapping categories: intentional and unintentional. ${ }^{14}$ Unintentional nonadherence occurs when the patient intends to follow the agreed treatment but is prevented from doing so by barriers that are beyond his or her control. Examples include poor recall or difficulties in understanding the instructions, inability to pay for the treatment, or simply forgetting to take it. Intentional nonadherence occurs when the patient decides not to follow the treatment recommendations. ${ }^{14}$ Numerous beliefs and preferences may influence the patient's perceptions of the pharmacological treatment and the motivation to start and continue with it. ${ }^{14}$

Analgesic nonadherence in patients with chronic pain is a frequent problem and a well-studied topic in the literature. ${ }^{13,15,16}$ In contrast, analgesic nonadherence in patients with acute pain is not well studied. ${ }^{17}$ An explanation for the paucity of information on this topic can be found in the fact that the prescription of analgesics for acute postoperative pain traditionally has been by the pro re nata convention or, in other words, "as needed." ${ }^{18}$ Nevertheless, numerous researchers have recommended the use of fixed-dose analgesic administration schedules during the initial 48-hour postoperative phase in order to maintain a steady blood level of the analgesic and keep the patient pain free. ${ }^{19}$ Consequently, pre-emptive use of analgesics in the treatment of acute pain has gained importance in the postoperative setting, and the incidence and determinants of patient adherence to these fixed-dose schedules need to be investigated. Identification of those patients at risk for analgesic nonadherence after day surgery may provide new insights for patient counseling, assistance with coping, and selection of future patients that might benefit from a planned overnight stay with the aim of prevention of the development of prolonged severe pain.

Therefore, the objective of our study was to analyze the prevalence and predictors of patient nonadherence to acute pain therapy at home after day surgery.

\section{METHODS}

\section{Patients}

This prospective longitudinal cohort study was approved by the Institutional Ethics Committee of the Maastricht University Medical Center, and all patients gave informed consent to participate. All patients undergoing day surgery were eligible to participate, regardless of the type of surgery. Exclusion criteria were (1) age $<18$ years, (2) inability to express themselves, (3) visual dysfunction, or (4) insufficient understanding of the Dutch language.

\section{Questionnaires}

Patients were asked to complete 2 successive questionnaire packages.

First, a baseline questionnaire package was used to measure demographics (eg, age, gender, work status, highest level of education), preoperative pain variables, psychological variables, previous surgery (related or not to the current surgery), and baseline quality of life (QOL). Preoperative pain variables included average preoperative pain intensity, expected postoperative pain intensity by the patient, interference of preoperative pain with daily activities, and preoperative analgesic use (yes/no). For measurements related to pain, an 11-point numeric rating scale (NRS; $0=$ no pain or interference of pain with daily activities, and $10=$ worst pain or interference imaginable) was used. Based on recent literature, we defined moderate postoperative pain as an NRS score of $>3$ and severe postoperative pain as an NRS score of $>5$ in this study. ${ }^{20,21}$ Psychological 
variables (ie, catastrophic thinking, personality trait optimism, fear of potential short- and long-term consequences of surgery) were analyzed based on 3 validated questionnaires, respectively: the Pain Catastrophizing Scale (PCS), Life Orientation Test Revised (LOT-R), and Surgical Fear Questionnaire (SFQ). ${ }^{22-25}$ For the PCS and LOT-R, shortened versions were used to minimize patient burden. ${ }^{2,26}$ The EuroQol (EQ-5D) questionnaire was used to analyze QOL. ${ }^{27}$

Second, a follow-up questionnaire package was used to measure adherence prescribed to pain medication, postoperative pain variables, postoperative QOL, and quality of recovery. The occurrence of postoperative nausea, type of prescribed analgesics, use of notprescribed analgesics, and number of postoperative healthcare visits were also monitored. To measure adherence to prescribed pain medication, patients were asked if they had used their analgesic medication as prescribed during the first 4 postoperative days, to which they responded "yes," “yes, sometimes," or "no." Postoperative pain variables included level of average acute postoperative pain over the first 4 postoperative days and origin (related or unrelated) of postoperative pain, interference of postoperative pain with daily activities, patient satisfaction with pain treatment, and percentage of pain relief by pain treatment. Finally, quality of recovery was measured with the 1-item global surgical recovery (GSR) index. The GSR index represents a single question about the extent to which patients considered themselves to be recovered from surgery ("if $100 \%$ recovery means your health is back to the same level as it was before the surgery, what percentage of recovery are you at now?").22,28

\section{Procedure}

Between November 2008 and April 2010, patients planned for day surgery and presenting at the outpatient clinic for preoperative assessment at the Maastricht University Medical Center, were asked to participate. The purpose and methods of the study were explained to the patient by the anesthesiologist or physician assistant performing the assessment. If consent was obtained, the patient received an envelope containing an informative letter about the study, the 2 questionnaire packages, and 2 return envelopes. Patients also received a standardized prescription for postoperative analgesics (ie, acetaminophen 1,000 mg 4 times a day, and acetaminophen/ tramadol 650/75 mg 4 times a day). Furthermore, patients received verbal and written instructions to start with acetaminophen and to switch to acetaminophen/ tramadol in case of insufficient analgesia.

Patients were instructed to complete the baseline questionnaire package 1 week before the surgical procedure. Patients who did not return this baseline questionnaire package were considered to be unwilling to participate, and no further attempts to contact them were made. The follow-up questionnaire package had to be completed at the fourth day after surgery. Patients who returned the baseline questionnaire package but did not return the follow-up questionnaire package were reminded by regular mail or telephone. Only patients who returned both the baseline and follow-up questionnaire packages were included into our analyses. All further clinical information (eg, American Society of Anesthesiologists [ASA] physical status, surgical procedure, type of anesthesia, and duration of the procedure) was acquired by systematic chart review.

\section{Outcome Measures}

The main outcome variable in this study was analgesic nonadherence. The level of analgesic adherence was defined according to the patient's response to the questionnaire item "analgesia use as prescribed": full adherence, "yes" (category 1); partial adherence, "yes, sometimes" (category 2); nonadherence, "no" (category 3).

\section{Statistical Analysis}

All baseline characteristics were presented as mean (standard deviation), median (25th to 75 th percentile), or absolute number (percentage). To assess baseline differences between the 3 adherence groups, we used analysis of variance (ANOVA), Kruskal-Wallis tests, and chi-square tests. For the main analyses, we dichotomized the 3 adherence groups into nonadherence (category 3) and adherence (category 1 and 2). For the prediction of nonadherence, we performed bivariate and multivariate logistic regression analyses, with nonadherence as the dependent variable. Potential predictors were entered in the multivariate model using stepwise backward elimination (criterion $P<0.10$ ). Age and sex were forced in the model, irrespective of statistical significance. An initial regression model was created with the preoperative variables education level, employment status, ASA classification, preoperative pain intensity, preoperative pain interference, expected postoperative pain intensity, preoperative analgesic use, 
fear of short- and long-term aspects of surgery, pain catastrophizing, optimism, and QOL. In the final regression model, the initial model was expanded by the per- and postoperative variables duration of surgery, type of anesthesia, postoperative pain, postoperative pain interference, and postoperative nausea. A final significance level of $P<0.05$ was chosen. To assess the ability of both the initial and final model to discriminate between adherent and nonadherent patients, the area under the curve (AUC) was calculated.

To prevent a potential loss of statistical power and precision, we used multiple imputation to impute any variables that were incompletely observed. The number of imputations was set to 10. Presented patient data in the results are based on the original data. The statistical results were pooled using Rubin's rules, except for $F$ and chi-square distributed statistics. These were pooled using the method described by Allison. ${ }^{29}$ Analyses were performed using IBM SPSS Statistics for Windows, Version 23.0 (IBM Corp., Armonk, NY, U.S.A.). The pooling of $F$ and chi-square statistics was performed in $\mathrm{R}$ version 3.3.3, The R Foundation (Vienna, Austria) using the miceadds package.

\section{RESULTS}

\section{General Characteristics}

During the study period, between November 2008 and April 2010, 2,500 patients were invited to participate; 1,396 patients $(56 \%)$ returned the baseline questionnaire. Ninety-two percent of these patients $(n=1,282)$ returned the follow-up questionnaire, of which 34 patients were excluded. This resulted in data of 1,248 patients for statistical analysis (Figure 1).

Baseline patient characteristics, including socio-economic status, psychological parameters, preoperative QOL, and preoperative pain characteristics are shown in Table 1, stratified by groups based on adherence. Mean (SD) age of all patients was 52.2 (14.6) years, 707 were female, and 541 were male. Most patients were classified as ASA I or II.

Baseline analyses revealed that, in general, both full and partial adherence groups showed the most similarities, as opposed to the nonadherence group. Based on these findings, further statistical testing was performed comparing the nonadherence group with the combined full and partial adherence group.

The nonadherence group differed significantly from the combined full and partial adherence group with regard to sex, employment status, QOL, surgical fear, pain catastrophizing, expected pain, preoperative pain intensity, preoperative pain interference, and preoperative analgesic use (see Table 1).

The nonadherence group differed also significantly from the combined full and partial adherence group with regard to duration of surgery, postoperative pain, postoperative pain interference, type of prescribed analgesic used, satisfaction with pain treatment, use of other than prescribed analgesics, origin of pain, postoperative nausea, GSR, and QOL (Table 2).

\section{Prevalence of Analgesic Nonadherence}

From a total of 1,248 patients, 706 were fully adherent (56.6\%), 250 were partially adherent $(20.0 \%)$, and 270 were nonadherent $(21.6 \%)$ (see Table 1$)$. Data on adherence was missing in 22 patients $(1.8 \%)$. The level of nonadherence for each NRS score of average postoperative pain during the study period is presented in Figure 2. Almost $60 \%$ of all patients with an NRS score of 0 were nonadherent. The proportion of nonadherent patients decreased as average pain intensity increased up to an NRS score of 6 . At pain intensity levels above a score of 6 , the proportion of nonadherence increased again. However, in absolute numbers nonadherence in patients with high pain scores is rather rare. Nonadherence was absent at the highest NRS level of 10. Additional results on adherence, postoperative pain, and postoperative nausea per homogenous surgical group, containing at least 20 procedures, are provided in Table S1.

Of all patients with moderate postoperative pain, 35 patients $(12.5 \%)$ were nonadherent $(2.8 \%$ of total population) and 67 patients $(24.1 \%)$ were partially adherent (5.4\% of total population). In the severe pain group, still 20 patients $(6.5 \%)$ were nonadherent $(1.6 \%$ of total population) and 49 patients $(16.0 \%)$ were partially adherent $(3.9 \%$ of total population). In the combined moderate-to-severe pain group, $9.4 \%$ and $19.8 \%$ of all patients were nonadherent or partially adherent, respectively.

\section{Prevalence of Use of Other than Prescribed Analgesics and Relationship Between Postoperative Pain Intensity and Use of Other than Prescribed Analgesics}

The highest proportion of patients who reported the use of other analgesics (paracetamol, nonsteroidal antiinflammatory drugs or opioids) than prescribed was 


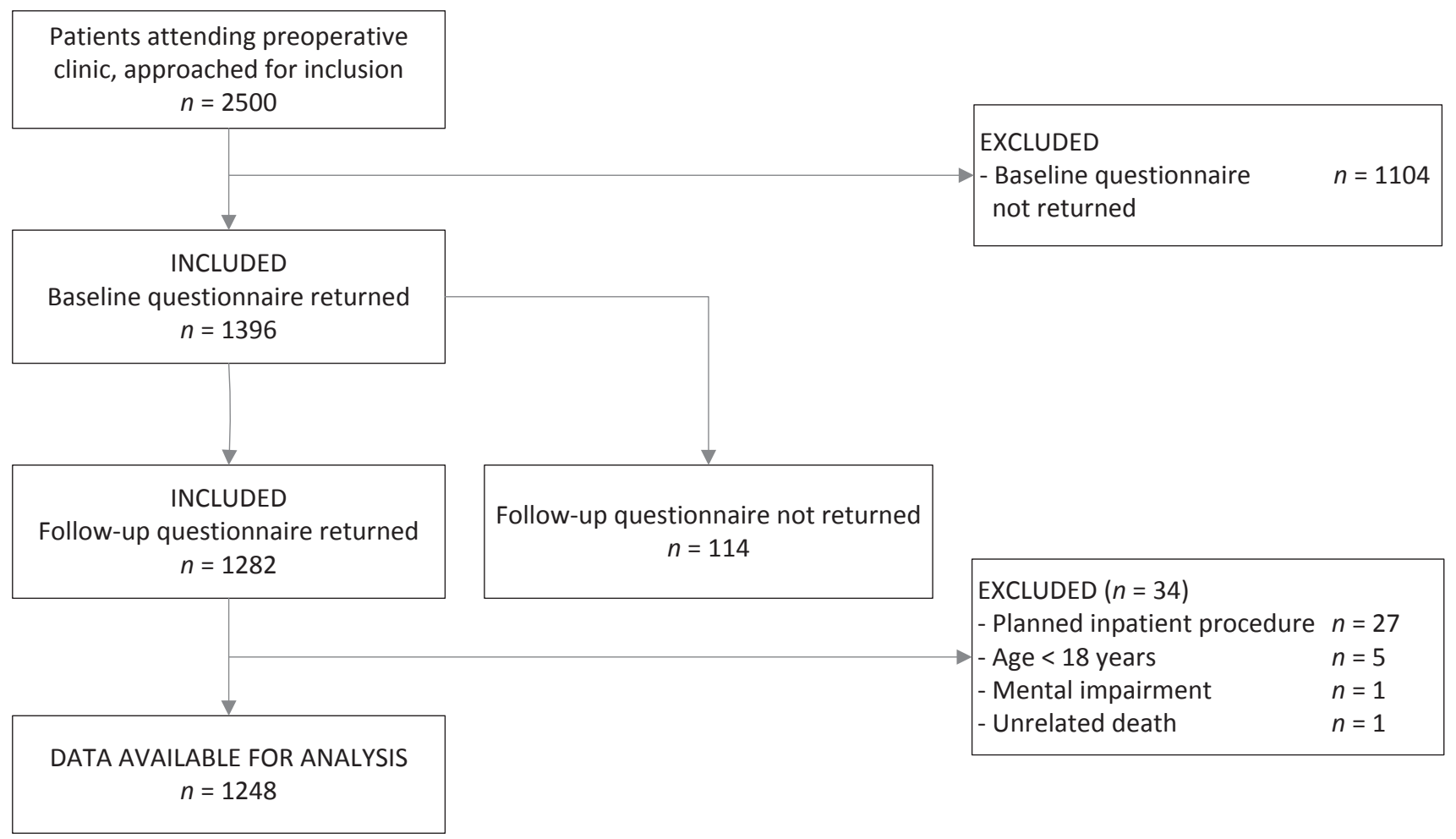

Figure 1. Flowchart depicting the inclusion and exclusion.

found in the nonadherence group (see Table 2). It is unknown whether the use of analgesics other than those prescribed was based on self-administration of overthe-counter medication, or based on prescription by other healthcare professionals such as the general practitioner.

Furthermore, other than prescribed analgesics were used by $9.5 \%$ of all patients with mild pain intensity (NRS score of 1 to $3 ; n=631$ ). A gradual increase in the proportion of patients using other than prescribed analgesics was observed in the moderate pain group $(n=280 ; 17.9 \%)$ and the severe pain group $(n=306$; $22.9 \%)$.

\section{Bivariate Logistic Regression Analyses}

Bivariate analyses showed male gender, high educational level (vs. low), paid work (vs. voluntary work), low shortterm and long-term surgical fear, and high QOL to have a positive association with analgesic nonadherence. All preoperative pain determinants (ie, preoperative pain, preoperative analgesic use, higher expected pain, and high levels of pain interference with daily activities) showed a negative association with nonadherence.

A short duration of surgery, low satisfaction with pain treatment, absence of postoperative nausea, high
QOL, and high GSR showed a positive association with analgesic nonadherence. Postoperative pain and high levels of pain interference with daily activities showed a negative association with nonadherence.

\section{Multivariate Logistic Regression Analysis}

An initial regression model created with the preoperative variables showed, after stepwise backward elimination, low preoperative pain, low preoperative expectations of pain, and low fear of short-term effects of surgery to be the most important predictors of nonadherence (Table 3). This resulted in a model with an AUC of 0.66 .

After extending the initial model with per and postoperative variables, the final regression model showed short duration of surgery and low levels of postoperative pain to be the most important predictors of nonadherence (see Table 3). None of the baseline predictors remained significant in this final model. This resulted in a model with an AUC of 0.77.

\section{DISCUSSION AND CONCLUSIONS}

This is the first large prospective cohort study to date assessing both prevalence and possible predictors of 
Table 1. Baseline Data per Group: Full, Partial, and No Adherence

\begin{tabular}{|c|c|c|c|c|}
\hline Baseline Measures & $\begin{array}{l}\text { Full Adherence } \\
n=706\end{array}$ & $\begin{array}{l}\text { Partial Adherence } \\
n=250\end{array}$ & $\begin{array}{l}\text { No Adherence } \\
n=270\end{array}$ & $P$ \\
\hline Age (years) & $51.5(14.8)$ & $53.4(14.2)$ & $52.4(14.3)$ & 0.198 \\
\hline Female & $406(58 \%)$ & $150(60 \%)$ & $135(50 \%)$ & 0.011 \\
\hline \multicolumn{5}{|l|}{ Education } \\
\hline Low & $55(8 \%)$ & $14(6 \%)$ & $13(5 \%)$ & \multirow[t]{4}{*}{0.085} \\
\hline Middle & $508(73 \%)$ & $175(71 \%)$ & $188(69 \%)$ & \\
\hline High & $132(19 \%)$ & $58(23 \%)$ & $69(26 \%)$ & \\
\hline Missing & 11 & 3 & 0 & \\
\hline \multicolumn{5}{|l|}{ Employment status } \\
\hline Paid job & $362(51 \%)$ & $112(45 \%)$ & $152(56 \%)$ & \multirow[t]{4}{*}{0.048} \\
\hline Voluntary/unpaid work & $118(17 \%)$ & $40(16 \%)$ & $31(12 \%)$ & \\
\hline Unemployed & $225(32 \%)$ & $98(39 \%)$ & $87(32 \%)$ & \\
\hline Missing & 1 & 0 & 0 & \\
\hline \multicolumn{5}{|l|}{ ASA classification } \\
\hline 1 & $361(52 \%)$ & $120(49 \%)$ & $141(53 \%)$ & \multirow[t]{4}{*}{0.224} \\
\hline II & $294(43 \%)$ & $117(47 \%)$ & $118(45 \%)$ & \\
\hline III & $37(5 \%)$ & $9(4 \%)$ & $6(2 \%)$ & \\
\hline Missing & 14 & 4 & 5 & \\
\hline EQ-5D $(-0.24$ to 1.0$)$ & $0.76(0.24)$ & $0.76(0.23)$ & $0.81(0.21)$ & 0.009 \\
\hline EQ-5D health status (0 to 100 ) & $72(18)$ & $72(18)$ & $75(18)$ & 0.055 \\
\hline Surgical fear (short-term, 0 to 40 ) & $15.5(9.8)$ & $14.6(9.2)$ & $11.6(9.1)$ & $<0.001$ \\
\hline Surgical fear (long-term, 0 to 40 ) & $10.5(9.0)$ & $10.9(8.4)$ & $8.1(7.2)$ & $<0.001$ \\
\hline Pain catastrophizing (6 to 30 ) & $12.9(4.3)$ & $13.0(4.1)$ & $12.2(4.0)$ & 0.067 \\
\hline Optimism (4 to 20) & $14.2(2.6)$ & $13.9(2.5)$ & $14.3(2.6)$ & 0.268 \\
\hline Expected pain (0 to 10 ) & $4(2$ to 6$)$ & $4(2$ to 6$)$ & $3(1$ to 5$)$ & $<0.001$ \\
\hline Preoperative pain (0 to 10 ) & $3(0$ to 6$)$ & $2(0$ to 5$)$ & 0 (0 to 4$)$ & $<0.001$ \\
\hline Pain interference (0 to 10$)$ & 2 (0 to 5$)$ & $1.5(0$ to 5$)$ & 0 (0 to 4$)$ & $<0.001$ \\
\hline Preoperative analgesic use & $204(29 \%)$ & $58(24 \%)$ & $43(16 \%)$ & $<0.001$ \\
\hline
\end{tabular}

$N=1,248$. Values are mean (SD), number (\%), or median (25th to 75 th percentile).

Original data on adherence of 22 patients are missing; baseline data not shown. Adherence was defined according to the patient's response to the questionnaire item "analgesia use as prescribed": full adherence, "yes"; partial adherence "yes, sometimes"; nonadherence, "no."

EQ-5D health status: Euroqol quality of life; surgical fear: Surgical Fear Questionnaire short- and long-term subscale; pain catastrophizing: Pain Catastrophizing Scale, items 5 and 12 for Helplessness, items 9 and 11 for Rumination, and items 6 and 13 for Magnification; optimism: Life Orientation Test revised, items 4, 7, 9, and 10; baseline pain: average pain last week, numeric rating scale (NRS); pain interference: impact pain on daily activities last week, NRS; expected pain: expected pain 4 days after surgery, NRS.

pain: expected pain 4 days after surgery, NRS.
$P$ value: comparison of the noncompliance group with the combined groups full and partial compliance. Statistical testing of pooled results, independent $t$-test, Mann-Whitney $U$ test, or chi-square, $P<0.05$. patient nonadherence to pharmacological acute pain therapy at home after day surgery. Possible predictors included patient characteristics, type and duration of surgery and anesthesia, pre- and postoperative painrelated variables, recovery characteristics, and social and psychological factors.

The results of the present study suggest that nonadherence and partial adherence to pharmacological acute pain therapy after day surgery are relatively high $(21.6 \%$ and $20.0 \%$, respectively). Furthermore, our study showed a strong and inverse relation between analgesic nonadherence and postoperative pain intensity. Consequently, analgesic nonadherence and partial adherence in patients with moderate to severe pain is less common (9.4\% and $19.8 \%$, respectively). Finally, short duration of surgery also predicted nonadherence.

Our data are in line with recent literature on analgesic nonadherence in chronic pain patients, as nonadherence rates in this patient population also range from $8 \%$ to $62 \%$, with a weighted mean of $40 \% .^{30}$ Data on the relationship between pain intensity and nonadherence in chronic pain patients are conflicting. ${ }^{17,30}$ In most studies, pain intensity has been shown to be negatively associated with nonadherence in chronic pain patients. ${ }^{31-34}$ On the other hand, pain intensity has also been documented to be positively associated with nonadherence in chronic pain patients. ${ }^{35,36}$ Finally, one study could not prove an association between chronic pain level and medication nonadherence. ${ }^{37}$ One study that also investigated the relationship between acute postoperative pain intensity and analgesic nonadherence also found a strong inverse relationship. ${ }^{17}$

Our data suggest that nonadherent patients are more inclined to take other than prescribed analgesics. Furthermore, we noted a positive association between acute postoperative pain intensity and the use of nonprescribed analgesics. A possible explanation for these findings might be that patients who experienced insufficient pain relief or adverse effects from prescribed pain medication were willing to stop their prescribed pain medication and/ or to use other pain medication, such as over-the-counter medication or that prescribed by other healthcare 


\begin{tabular}{|c|c|c|c|c|}
\hline & $\begin{array}{l}\text { Full Adherence } \\
n=706\end{array}$ & $\begin{array}{l}\text { Partial Adherence } \\
n=250\end{array}$ & $\begin{array}{l}\text { No Adherence } \\
n=270\end{array}$ & $P$ \\
\hline Duration of surgery (minutes) & $52.3(35.3)$ & $45.2(29.4)$ & $40.9(32.4)$ & $<0.001$ \\
\hline \multicolumn{5}{|l|}{ Type of anesthesia } \\
\hline General & $571(81 \%)$ & $189(76 \%)$ & $210(78 \%)$ & \multirow[t]{4}{*}{0.350} \\
\hline Locoregional & $95(13 \%)$ & $47(19 \%)$ & $44(17 \%)$ & \\
\hline $\begin{array}{l}\text { Combined general and } \\
\text { locoregional }\end{array}$ & $40(6 \%)$ & $13(5 \%)$ & $14(5 \%)$ & \\
\hline Missing & 0 & 1 & 2 & \\
\hline Postoperative pain (0 to 10 ) & 4 (3 to 6$)$ & 3 (2 to 5$)$ & 2 (0 to 3$)$ & $<0.001$ \\
\hline Pain interference (0 to 10$)$ & 5 (3 to 8$)$ & 4 (2 to 7$)$ & 1.5 (0 to 5$)$ & $<0.001$ \\
\hline \multicolumn{5}{|l|}{ Prescribed analgesic used } \\
\hline Not & $1(<1 \%)$ & 0 & $269(99 \%)$ & \multirow[t]{5}{*}{$<0.001$} \\
\hline Paracetamol & $453(65 \%)$ & $183(74 \%)$ & $1(<1 \%)$ & \\
\hline Zaldiar & $96(14 \%)$ & $26(11 \%)$ & 0 & \\
\hline Paracetamol and zaldiar & $150(21 \%)$ & $38(15 \%)$ & 0 & \\
\hline Missing & 6 & 3 & 0 & \\
\hline Pain relief ( $0 \%$ to $100 \%)$ & 70 (50 to 80$)$ & 70 (50 to 90$)$ & NA & NA \\
\hline \multicolumn{5}{|l|}{ Satisfaction with pain treatment } \\
\hline Very unsatisfied & $76(11 \%)$ & $28(11 \%)$ & $21(8 \%)$ & \multirow[t]{5}{*}{$<0.001$} \\
\hline A little or moderately satisfied & $186(27 \%)$ & $44(18 \%)$ & $12(4 \%)$ & \\
\hline Very satisfied & $352(50 \%)$ & $118(48 \%)$ & $39(15 \%)$ & \\
\hline $\begin{array}{l}\text { Not applicable } \\
\text { (no/negligible pain) }\end{array}$ & $85(12 \%)$ & $57(23 \%)$ & $194(73 \%)$ & \\
\hline Missing & 7 & 3 & 4 & \\
\hline Use other analgesics & $100(14 \%)$ & $15(6 \%)$ & $63(24 \%)$ & $<0.001$ \\
\hline \multicolumn{5}{|l|}{ Origin of pain } \\
\hline Not surgery-related & $23(4 \%)$ & $5(2 \%)$ & $7(3 \%)$ & \multirow[t]{5}{*}{$<0.001$} \\
\hline Surgery-related & $435(63 \%)$ & $122(51 \%)$ & $64(25 \%)$ & \\
\hline Unknown & $36(5 \%)$ & $20(8 \%)$ & $9(3 \%)$ & \\
\hline Not applicable (no pain) & $193(28 \%)$ & $93(39 \%)$ & $177(69 \%)$ & \\
\hline Missing & 19 & 10 & 13 & \\
\hline Postoperative nausea & $217(31 \%)$ & $62(25 \%)$ & $45(17 \%)$ & \multirow[t]{2}{*}{$<0.001$} \\
\hline $\begin{array}{l}\text { Global surgical recovery } \\
(0 \% \text { to } 100 \%)\end{array}$ & $58.8(24.1)$ & $65.2(22.1)$ & $73.0(26.2)$ & \\
\hline EQ-5D $(-0.59$ to 1.0$)$ & $0.63(0.30)$ & $0.71(0.24)$ & $0.79(0.23)$ & $<0.001$ \\
\hline EQ-5D health status (0 to 100 ) & $69(19)$ & $73(16)$ & $78(17)$ & $<0.001$ \\
\hline \multicolumn{5}{|l|}{ Healthcare visits } \\
\hline 0 & $640(91 \%)$ & $234(93 \%)$ & $254(94 \%)$ & \multirow[t]{3}{*}{0.301} \\
\hline 1 & $46(6 \%)$ & $12(5 \%)$ & $10(4 \%)$ & \\
\hline$>1$ & $20(3 \%)$ & $4(2 \%)$ & $6(2 \%)$ & \\
\hline
\end{tabular}

Table 2. Per- and Postoperative Results per Group: Full, Partial, and No Adherence

$N=1,248$. Values are mean (SD), number (\%), or median (25th to 75 th percentile). Original data on adherence of 22 patients are missing (baseline data not shown). Adherence was defined according to the patient's response to the questionnaire item "analgesia use as prescribed": full adherence, "yes"; partial adherence, "yes, sometimes"; nonadherence, "no."

Pain: average pain over the first 4 postoperative days, numeric rating scale (NRS); pain interference: impact pain on daily activities over the first 4 postoperative days, NRS; pain relief: pain relief as result of medication, over the past 24 hours, 4 days after surgery (0\% to $100 \%$; in the no adherence group, $76 \%$ indicated not applicable; therefore, no results are shown for this group); use other analgesia: paracetamol, NSAID, or opioid; EQ-5D health status: Euroqol quality of life 0 to 100; healthcare visits: post-discharge visit to general practitioner, emergency room, or specialist because of pain.

$P$ value: comparison of the noncompliance group with the combined groups full and partial compliance. Statistical

testing of pooled results, independent $t$-test, Mann-Whitney $U$ test, or chi-square, $P<0.05$.

professionals. It has to be pointed out that the combined use of prescribed and nonprescribed analgesics carries the risk of serious adverse drug events due to overdose and toxicity as for instance with paracetamol.

Another primary goal of this study was to identify predictors of patient nonadherence to acute pain therapy at home after day surgery. Bivariate analysis of all preoperative variables showed male gender, high educational level, paid work, low short-term and long-term surgical fear levels and high EQ-5D health status to be positively associated with nonadherence. The preoperative pain variables (ie, preoperative pain, preoperative analgesic use, higher expected pain, and high levels of pain interference with daily activities) were shown to be negatively associated with nonadherence. The observed association between high educational level and nonadherence is in line with a previous study on nonadherence in chronic pain patients. ${ }^{30}$ Highly educated patients may use more active coping strategies or self-medication to improve their pain symptoms and/or may have more concerns about prescribed pain medication.

Bivariate analysis of all perioperative variables showed short duration of surgery, low satisfaction with pain treatment, absence of postoperative nausea, high 


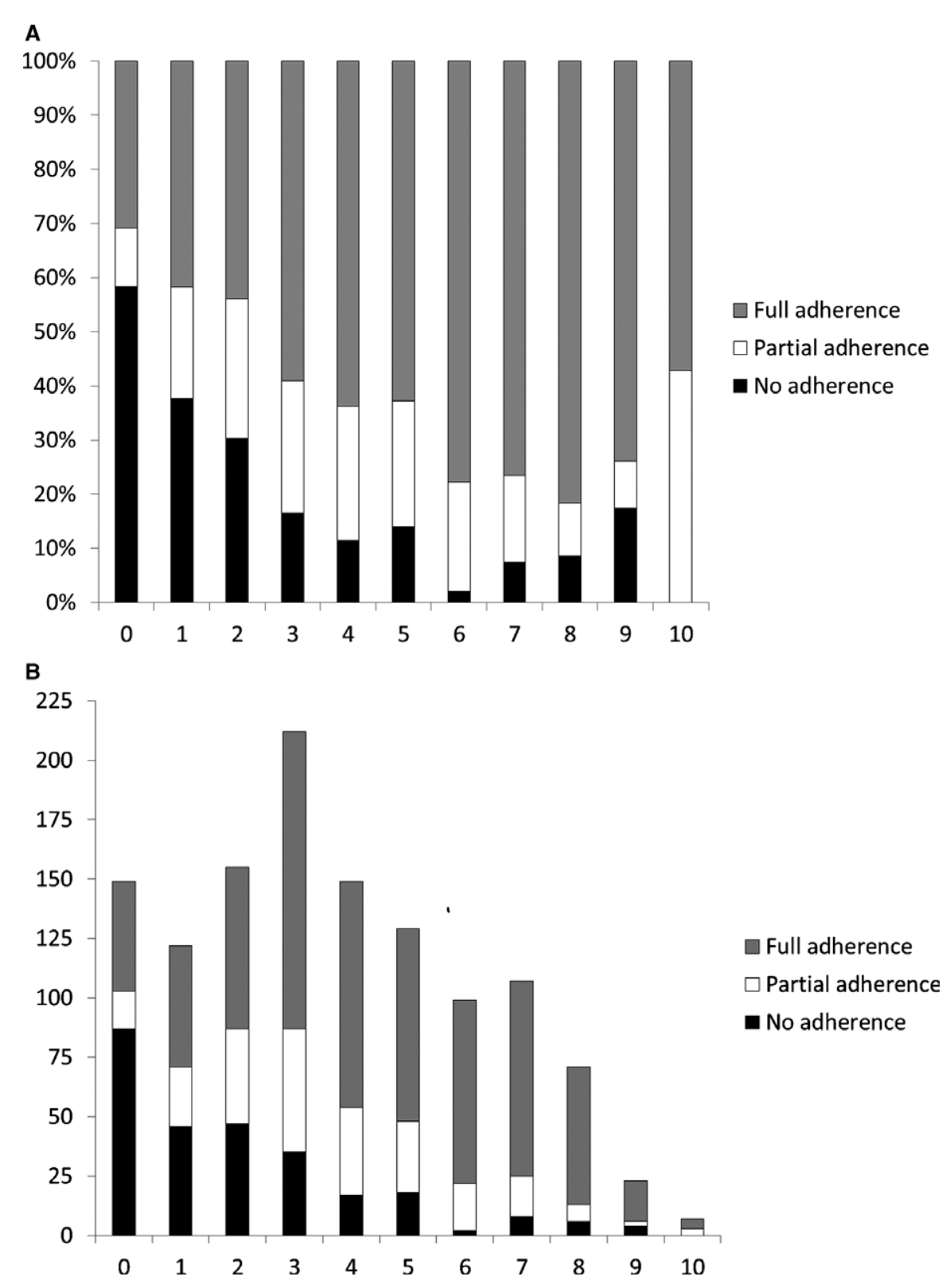

Figure 2. Adherence in relation to postoperative pain score NRS 0 to 10 . (A) Percentage. (B) Patient numbers.

EQ-5D health status, and high GSR to be positively associated with analgesic nonadherence. Postoperative pain and high levels of pain interference with daily activities were negatively associated with nonadherence. The negative association between analgesic nonadherence and postoperative nausea is rather surprising. One could presume that patients would stop taking their prescribed analgesic (acetaminophen/tramadol) if they experienced postoperative nausea as an adverse effect. Nevertheless, patients with high pain scores were willing to continue their analgesic therapy despite the associated adverse effects. Furthermore, pain itself has been associated with postoperative nausea. ${ }^{38}$ Consequently, the apparent negative association between postoperative nausea and nonadherence can be explained by the negative association between pain intensity and nonadherence. Our logistic regression model confirmed this hypothesis as postoperative nausea fell out of this final model.

A model created with all the preoperative variables to preoperatively predict nonadherence showed that low preoperative pain intensity, low preoperative expectations of pain, and low fear of short-term effects of surgery were the most important preoperative predictors of nonadherence. The predictive power of these 3 variables in the preoperative model is not surprising 


\begin{tabular}{|c|c|c|c|c|}
\hline & \multicolumn{2}{|c|}{ Initial Model (Preoperative) } & \multicolumn{2}{|c|}{ Final Model (Perioperative) } \\
\hline & Odds Ratio $(95 \% \mathrm{Cl})$ & $P$ & Odds Ratio $(95 \% \mathrm{Cl})$ & $P$ \\
\hline Intercept & 0.80 (0.42 to 1.53$)$ & 0.505 & 3.09 (1.48 to 6.45$)$ & 0.003 \\
\hline Age & 1.00 (0.99 to 1.01$)$ & 0.588 & 0.99 (0.98 to 1.00$)$ & 0.094 \\
\hline \multicolumn{5}{|l|}{ Sex } \\
\hline Female & Reference & & Reference & \\
\hline Male & 1.29 (0.97 to 1.72$)$ & 0.083 & 1.34 (0.99 to 1.82$)$ & 0.057 \\
\hline \multicolumn{5}{|l|}{ ASA classification } \\
\hline ASA I & Reference & & Reference & \\
\hline ASA II & 1.01 (0.73 to 1.39$)$ & 0.952 & 0.98 (0.70 to 1.37$)$ & 0.891 \\
\hline ASA III & $0.42(0.17$ to 1.03$)$ & 0.057 & $0.46(0.18$ to 1.18$)$ & 0.106 \\
\hline Preoperative pain & 0.93 (0.88 to 0.99$)$ & 0.015 & $1.00(0.94$ to 1.06$)$ & 0.897 \\
\hline Expected pain & 0.85 (0.79 to 0.92$)$ & $<0.001$ & 0.95 (0.88 to 1.03$)$ & 0.239 \\
\hline Short-term surgical fear & 0.98 (0.96 to 1.00$)$ & 0.025 & $0.99(0.97$ to 1.00$)$ & 0.109 \\
\hline Duration of surgery & NA & & $0.99(0.99$ to 1.00$)$ & 0.001 \\
\hline Postoperative pain & NA & & 0.73 (0.65 to 0.82 ) & $<0.001$ \\
\hline $\begin{array}{l}\text { Postoperative pain } \\
\text { interference }\end{array}$ & NA & & 0.93 (0.86 to 1.01$)$ & 0.087 \\
\hline
\end{tabular}

Odds ratio and $95 \%$ confidence interval (CI) have been rounded to 2 decimals. Area under the curve (AUC) of model $1=0.66 ;$ model $2=0.77$

ASA, American Society of Anesthesiologists.

Bold indicates results of the logistic regression analysis for prediction of nonadherence. An initial regression model was created with the preoperative variables. The final model was extended with per- and postoperative variables.
Table 3. Prediction of Nonadherence: Multivariate Logistic Regression Models since they all have a strong positive association with postoperative pain intensity. ${ }^{39,40}$

After extending the preoperative model with Per- and postoperative variables, the final model showed low postoperative pain level to be the most important predictor of analgesic nonadherence together with a short-duration surgery. All the preoperative variables lost significance in this final model. The inverse correlation between length of surgery and analgesic nonadherence is also expected since longer operations are associated with more enduring nociceptive input, which may increase the chance of central sensitization, and subsequently persistent pain. ${ }^{22}$

Improving adherence to pharmacological pain treatment is clinically relevant in those patients with moderate to severe pain. Interventions to improve analgesic adherence include better patient education, telephone follow-up, electronic reminders, and monitoring systems (eg, short message service text messaging and real-time medication monitoring linked to smart pill containers). ${ }^{30,41}$ Regular assessments of analgesic adherence by telephone follow-up have the advantage that it can be combined with assessments of pain relief by prescribed analgesics. If necessary, analgesic therapy can be tailored to individual patient needs.

The present study also has some limitations. Firstly, we didn't specifically ask patients the reason for analgesic nonadherence. As a consequence, we are not able to differentiate between unintentional or intentional nonadherence. Therefore, we can only speculate on the exact relationship between nonadherence and the factors associated with it. For example, analgesic nonadherence may be associated with male sex because male patients have an increased risk for forgetting to take their medication (unintentional) or because male patients experience less pain than women or are more unwilling to take their medication because of side-effects (intentional). Secondly, this is a questionnaire-based survey, and the response rate was $51 \%$ for both the baseline and follow-up questionnaire. Hence, there is a possible danger of selection bias. Still, the response rate is similar to those of other questionnaire-based surveys. Thirdly, we used self-report to measure medication nonadherence. This is a subjective method that tends to underestimate nonadherence. ${ }^{42}$ In contrast, objective methods, such as urine analysis, are generally more reliable for monitoring nonadherence. These objective methods, however, are expensive and difficult to implement in a home setting, and furthermore, they may partly be considered as an adherence intervention. ${ }^{30}$ There is no gold standard approach to the measurement of nonadherence as all methods have pros and cons. Nevertheless, a patient-centered approach with patientreported information as a measure of medication adherence has recently been advocated. ${ }^{41}$ Fourthly, we did not clearly differentiate between medication underuse and overuse, a distinction often made in medication nonadherence in chronic patients. ${ }^{13,30}$ In our patient cohort, medication nonadherence mainly refers to medication underuse. The use of nonprescribed analgesics may partially refer to medication overuse. Finally, patients enrolled in the present study were 
postoperatively treated with a combination of paracetamol and a weak opioid, tramadol. Most postoperative regimens in the United States, however, are based on strong opioids. Therefore, the generalizability of our results can be questioned. More specifically, the threat of overuse and subsequent opioid addiction because of a feeling of well-being may be more present in the United States.

In conclusion, our data demonstrate that analgesic nonadherence and partial adherence in a large cohort of day surgery patients are common $(21.6 \%$ and $20.0 \%$, respectively). Analgesic nonadherence and partial adherence in day surgery patients with moderate to severe pain are less common $(9.4 \%$ and $19.8 \%$, respectively). Low postoperative pain intensity and short duration of surgery were the most important predictors of analgesic nonadherence. The most important preoperative predictors for analgesic nonadherence were low preoperative pain intensity, low preoperative expectations of pain, and low fear of short-term effects of surgery.

\section{ACKNOWLEDGEMENTS}

This research did not receive any specific grant from funding agencies in the public, commercial, or not-forprofit sectors.

\section{CONFLICT OF INTEREST}

The authors state that they don't have any conflict of interest.

\section{SUPPORTING INFORMATION}

Additional Supporting Information may be found in the online version of this article:

Table S1. Adherence, Pain, and Nausea per type of surgery.

\section{REFERENCES}

1. Wu CL, Berenholtz SM, Pronovost PJ, Fleisher LA. Systematic review and analysis of postdischarge symptoms after outpatient surgery. Anesthesiology. 2002;96:994-1003.

2. Rawal N. Postoperative pain treatment for ambulatory surgery. Best Pract Res Clin Anaesthesiol. 2007;21:129-148.

3. Gramke HF, de Rijke JM, van Kleef M, et al. The prevalence of postoperative pain in a cross-sectional group of patients after day-case surgery in a university hospital. Clin J Pain. 2007;23:543-548.

4. McGrath B, Elgendy H, Chung F, Kamming D, Curti B, King $S$. Thirty percent of patients have moderate to severe pain $24 \mathrm{hr}$ after ambulatory surgery: a survey of 5,703 patients. Can I Anaesth. 2004;51:886-891.

5. Beauregard L, Pomp A, Choiniere M. Severity and impact of pain after day-surgery. Can J Anaesth. 1998;45:304-311.

6. Kehlet H, Jensen TS, Woolf CJ. Persistent postsurgical pain: risk factors and prevention. Lancet. 2006;367:16181625.

7. Shipton EA. The transition from acute to chronic post surgical pain. Anaesth Intensive Care. 2011;39:824-836.

8. Hoofwijk DM, Fiddelers AA, Peters ML, et al. Prevalence and predictive factors of chronic postsurgical pain and poor global recovery one year after outpatient surgery. Clin J Pain. 2015;31:1017-1025.

9. Fortier J, Chung F, Su J. Unanticipated admission after ambulatory surgery-a prospective study. Can J Anaesth. 1998;45:612-619.

10. Pavlin DJ, Chen C, Penaloza DA, Polissar NL, Buckley FP. Pain as a factor complicating recovery and discharge after ambulatory surgery. Anesth Analg. 2002;95:627-634.

11. Segerdahl M, Warren-Stomberg M, Rawal N, Brattwall M, Jakobsson J. Clinical practice and routines for day surgery in Sweden: results from a nation-wide survey. Acta Anaesthesiol Scand. 2008;52:117-124.

12. Urquhart J. Patient non-compliance with drug regimens: measurement, clinical correlates, economic impact. Eur Heart J. 1996;17(suppl A):8-15.

13. Butow P, Sharpe L. The impact of communication on adherence in pain management. Pain. 2013;154(suppl 1): S101-S107.

14. Maione S, Radanova L, De Gregorio D, et al. Effects of metabolites of the analgesic agent dipyrone (metamizol) on rostral ventromedial medulla cell activity in mice. Eur J Pharmacol. 2015;748:115-122.

15. Broekmans S, Dobbels F, Milisen K, Morlion B, Vanderschueren S. Medication adherence in patients with chronic non-malignant pain: is there a problem? Eur J Pain. 2009;13:115-123.

16. Monsivais D, McNeill J. Multicultural influences on pain medication attitudes and beliefs in patients with nonmalignant chronic pain syndromes. Pain Manage Nurs. 2007;8:64-71.

17. Stessel B, Theunissen M, Fiddelers AA, et al. Controlled-release oxycodone versus naproxen at home after ambulatory surgery: a randomized controlled trial. Curr Ther Res Clin Exp. 2014;76:120-125.

18. Manias E. Medication trends and documentation of pain management following surgery. Nurs Health Sci. 2003;5:85-94.

19. Conlon JA, O’Mathúna DP, O’Hare B. As required versus fixed schedule analgesic administration schedules for treating postoperative pain in children and adults (protocol). Cochrane Library. 2009;(10). 
20. Dihle A, Helseth S, Paul SM, Miaskowski C. The exploration of the establishment of cutpoints to categorize the severity of acute postoperative pain. Clin J Pain. 2006;22: $617-624$.

21. Gerbershagen HJ, Rothaug J, Kalkman CJ, Meissner W. Determination of moderate-to-severe postoperative pain on the numeric rating scale: a cut-off point analysis applying four different methods. Br J Anaesth. 2011;107:619-626.

22. Peters ML, Sommer M, de Rijke JM, et al. Somatic and psychologic predictors of long-term unfavorable outcome after surgical intervention. Ann Surg. 2007;245:487-494.

23. Sullivan MJL, Bishop SR, Pivik J. The Pain Catastrophizing Scale: development and validation. Psychol Assess. 1995;7:524-532.

24. Scheier MF, Carver CS, Bridges MW. Distinguishing optimism from neuroticism (and trait anxiety, self-mastery, and self-esteem): a reevaluation of the Life Orientation Test. $J$ Pers Soc Psychol. 1994;67:1063-1078.

25. Theunissen M, Peters ML, Schouten EG, et al. Validation of the surgical fear questionnaire in adult patients waiting for elective surgery. PLoS One. 2014;9:e100225.

26. Stessel B, Fiddelers AA, Joosten EA, Hoofwijk DM, Gramke HF, Buhre WF. Prevalence and predictors of quality of recovery at home after day surgery. Medicine (Baltimore). 2015;94:e1553.

27. Van Agt HM, Essink-Bot ML, Krabbe PF, Bonsel GJ. Test-retest reliability of health state valuations collected with the EuroQol questionnaire. Soc Sci Med. 1994;39: 1537-1544.

28. Kleinbeck SV. Self-reported at-home postoperative recovery. Res Nurs Health. 2000;23:461-472.

29. Allison PD. Missing Data van Quantitative Applications in the Social Sciences. SAGE Publications, Thousand Oaks, CA; 2001. ISBN 0761916725, 9780761916727.

30. Timmerman L, Stronks DL, Groeneweg JG, Huygen FJ. Prevalence and determinants of medication non-adherence in chronic pain patients: a systematic review. Acta Anaesthesiol Scand. 2016;60:416-431.

31. Broekmans S, Dobbels F, Milisen K, Morlion B, Vanderschueren S. Determinants of medication underuse and medication overuse in patients with chronic non-malignant pain: a multicenter study. Int J Nurs Stud. 2010;47:14081417.

32. Blamey R, Jolly K, Greenfield S, Jobanputra P. Patterns of analgesic use, pain and self-efficacy: a cross-sectional study of patients attending a hospital rheumatology clinic. BMC Musculoskel Disord. 2009;10:137.

33. Giannopoulos S, Kosmidou M, Sarmas I, et al. Patient compliance with SSRIs and gabapentin in painful diabetic neuropathy. Clin J Pain. 2007;23:267-269.

34. Rosser BA, McCracken LM, Velleman SC, Boichat C, Eccleston C. Concerns about medication and medication adherence in patients with chronic pain recruited from general practice. Pain. 2011;152:1201-1205.

35. Markotic F, Cerni Obrdalj E, Zalihic A, et al. Adherence to pharmacological treatment of chronic nonmalignant pain in individuals aged 65 and older. Pain Med. 2013;14: 247-256.

36. Stern A, Sanchez-Magro I, Rull M. Chronic noncancer pain intensity is inversely related to analgesic adherence in pain clinics. J Med Econ. 2011;14:568-575.

37. Matteliano D, Chang YP. Describing prescription opioid adherence among individuals with chronic pain using urine drug testing. Pain Manage Nurs. 2015;16:51-59.

38. Singla N, Pong A, Newman K. Combination oxycodone $5 \mathrm{mg} /$ ibuprofen $400 \mathrm{mg}$ for the treatment of pain after abdominal or pelvic surgery in women: a randomized, doubleblind, placebo- and active-controlled parallel-group study. Clin Ther. 2005;27:45-57.

39. Gramke HF, de Rijke JM, van Kleef M, et al. Predictive factors of postoperative pain after day-case surgery. Clin J Pain. 2009;25:455-460.

40. Sommer M, de Rijke JM, van Kleef M, et al. Predictors of acute postoperative pain after elective surgery. Clin J Pain. 2010;26:87-94.

41. Marcum ZA, Sevick MA, Handler SM. Medication nonadherence: a diagnosable and treatable medical condition. JAMA. 2013;309:2105-2106.

42. LaFleur J, Oderda GM. Methods to measure patient compliance with medication regimens. I Pain Palliat Care Pharmacother. 2004;18:81-87. 